\title{
Effect of Tube Geometry on Regenerative Cooling Performance
}

\author{
Daniel K. Parris" and D. Brian Landrum. ${ }^{\dagger}$ \\ Propulsion Research Center, The University of Alabama in Huntsville, Huntsville, Alabama, 35899
}

The flowfield characteristics in a rocket engine coolant channels are analyzed by use of a commercial CFD and multiphysics software developed by the CFD Research Corp. called CFD-ACE + . The channels are characterized by high Reynolds number flow, varying aspect ratio, varying curvature, asymmetric and symmetric heating. The supercritical hydrogen coolant introduces large property variations that have a strong influence on the developing flow and the resulting heat transfer. This paper only shows the effect of aspect ratio and curvature for constant properties.

\section{Nomenclature}

$\begin{array}{ll}\Delta p & =\text { Pressure Drop } \\ T_{m, i} & =\text { Bulk Inlet Temperature } \\ T_{m o} & =\text { Bulk Outlet Temperature } \\ T_{s, o} & =\text { Outlet Wall Temperature } \\ \rho & =\text { Density } \\ \mu & =\text { Viscosity } \\ k & =\text { Thermal Conductivity } \\ \mathrm{C}_{\mathrm{p}} & =\text { Constant Pressure Specific Heat } \\ D & =\text { cylinder diameter } \\ P & =\text { Perimeter } \\ L & =\text { Channel Length } \\ \dot{m} & =\text { Mass Flow Rate } \\ V & =\text { Velocity } \\ q_{c o n v} & =\text { Total Heat Transfer Rate } \\ q_{s}^{\prime \prime} & =\text { Constant Surface Heat Flux } \\ h & =\text { Heat Transfer Coefficient } \\ f & =\text { Friction Factor } \\ R_{D} & =\text { Reynolds Number } \\ P r & =\text { Prandtl Number } \\ N u_{D} & =\text { Nusselt Number }\end{array}$

\section{Introduction}

Because of high combustion temperatures and high heat transfer rates from the hot gases to the walls of the thrust chamber, cooling is a major design consideration in a rocket engine. There are many types of cooling. One of the most common and the one of particular interest in this paper is regenerative cooling. Regenerative cooling is normally used to protect the walls from the severe thermal environment that it sees during the combustion process. In most regeneratively cooled engines, the coolant passages are rectangular in shape. These tubes run the length on the combustor with the coolant entering the supersonic end, passing through the throat of the combustor, and exiting near the injector face. Liquid hydrogen is a typical coolant, and the pressures seen inside the thrust chamber are sufficient to ensure that the fluid remains supercritical throughout the combustion process.

\footnotetext{
* Graduate Research Assistant, Member, AIAA

${ }^{\dagger}$ Associate Professor of Mechanical and Aerospace Engineering, Associate Fellow AIAA

This material is a work of the U.S. Government and is not subject to copyright protection in the United States.
} 
Even though the designs of these cooling passages are critical for success, their heat transfer characteristics are not fully understood. The heat transfer characteristics of rectangular tubes differ in many ways to those of circular tubes. One clear difference is the way the fluid is heated. Heat transfer research often entails the use of an electrically heated circular tube, which is not representative of typical applications. Most regen tubes are heated from one side only. The combination of highly conductive materials and the milled rectangular passages that are used in design of the combustor body provides a fin effect between adjacent coolant passages which makes the rectangular cavities more effective. Also the curvature introduced by the shape of the combustor generates vortices inside the channels which enhance the heat transfer. Another factor is the strong compressibility of supercritical hydrogen. This strong compressibility will certainly have an effect on the flowfield. With all these different phenomena that occur inside the tube, the aspect ratio that is used in the combustor design represents a key factor that can be used to optimize the transfer of heat from the chamber walls to the coolant fluid.

To understand the heat transfer environment inside these rectangular tubes, the simple case of a straight rectangular tube is considered. Even in straight channels the flow field remains complex due to the fin effect, high Reynolds number, and the supercritical coolant. The supercritical conditions inside the coolant passages of rocket engines yield fluid properties that are strong functions of both pressure and temperature. The specific property variations that must be considered are specific heat, thermal conductivity, density and viscosity. The current study will only deal with constant properties. Variable property comparisons are left to future investigations.

\section{Code Validation}

In any numerical simulation, questions directed to the accuracy of the results always arise. Because of this, code validation is a must to give credibility to the results. Since we are dealing with a high Reynolds number flow, the turbulent $y+$ value must be taken into account along with the grid mesh to insure that proper flow characteristics are being simulated. Also, since we are heating the tubes, validation of the temperature prediction must be made.

Although we are studying the heat transfer effects in rectangular passages with high aspect ratio, with and without curvature, we first need validate the code using a simple case that is well known. One case that is well documented is circular tubes with constant surface heat flux. Temperature and pressure drop predictions are very important for the design of regenerative cooling passages. Therefore, if the commercial software can predict the pressure drop, bulk outlet temperature and surface temperature with some accuracy, then the results obtained for rectangular passages can be accepted with some degree of comfort. Typical tube conditions for regenerative cooled engines were used. The tube diameter used is $2 \mathrm{~mm}$ with a tube length of $34.25 \mathrm{~mm}$. The inlet fluid temperature is set to $40 \mathrm{~K}$, with an inlet mass flow rate of $5.516 \mathrm{E}-06 \mathrm{~kg} / \mathrm{s}$. A constant surface heat flux $100,000 \mathrm{~W} / \mathrm{m}^{2}$ is applied to the wall. Thermal physical properties for supercritical hydrogen at $40 \mathrm{~K}$, such that the Reynolds number is 10,000 is taken from Ref. 1. To calculate the outlet temperature, the following energy balance equation is employed along with the constant surface heat flux equation ${ }^{2}$.

$$
\begin{gathered}
q_{\text {conv }}=\dot{m} c_{p}\left(T_{m, o}-T_{m, i}\right) \\
q_{\text {conv }}=q_{s}^{\prime \prime}(P \bullet L)
\end{gathered}
$$

Utilizing equations (1) and (2), the bulk outlet temperature equation is

$$
T_{m, o}=\frac{\pi D L q_{s}^{\prime \prime}}{\dot{m} c_{p}}+T_{m, i}
$$

Now to find the surface temperature at the outlet, we need Newton's Law of cooling ${ }^{2}$.

$$
q_{s}^{\prime \prime}=h\left(T_{s, o}-T_{m, o}\right)
$$

To find $h$, the turbulent Nusselt number correlation by Dittus-Boelter is employed ${ }^{2}$.

$$
N u_{D}=\frac{h D}{k}=0.23 \operatorname{Re}_{D}^{4 / 5} \operatorname{Pr}^{0.4}
$$


To find the pressure drop, we need the following equation derived from the Darcy-Weisbach equation and the friction factor $f$ from the Moody chart $^{3}$.

$$
\Delta p=f \frac{\rho L V^{2}}{2 D}
$$

From the Moody chart, $f$ is approximately 0.0309 for a smooth tube of Reynolds number 10,000 . The results of the theoretical and numerical calculation are shown in Table 1 below.

\begin{tabular}{|c|c|c|c|}
\hline & $\begin{array}{c}\text { Bulk Outlet Temperature } \\
(\mathrm{K})\end{array}$ & $\begin{array}{c}\text { Outlet Wall Temperature } \\
(\mathrm{K})\end{array}$ & $\begin{array}{c}\text { Pressure Drop } \\
(\mathrm{Pa})\end{array}$ \\
\hline Theoretical & 51.08 & 116.43 & 2.899 \\
\hline CFD & 53.82 & 112.7 & 3.208 \\
\hline
\end{tabular}

Table 1: Numerical and Theoretical comparison

For our numerical simulation, we used a $\kappa-\varepsilon$ turbulence model, a turbulent Prandtl number of 0.9 , and a fixed pressure outlet boundary condition. The $\kappa-\varepsilon$ turbulence model is a standard turbulence model. It is a high Reynolds number model that uses wall functions for cells that are adjacent to the wall. CFD Research Corp. recommends a turbulent $y+$ value between 30 and 150 for the first cell adjacent to the wall. The mesh used is shown if Figure 1 and Figure 2. The grid that is shown in Figure 1 is a cross section of the pipe and shows grid stretching away from the wall. Figure 2 shows the grid for the length of the pipe and is stretched toward the inlet to aid in flow development. This mesh consists of 50,000 nodes. Also, we set the turbulent kinetic energy according to the turbulent intensity of 0.051 and a specific dissipation rate based on hydraulic diameter 0.002 .

In Figure 3, we can see the streamwise contours of pressure, velocity and temperature. From Table 1, we can see that the numerical model prediction is close to that of the analytical solution. The numerical model varies less than $6 \%$ for the bulk outlet temperature and the outlet surface temperature than that of the analytical solution. The pressure drop for the code is around $10.7 \%$ off from the analytical solution. Overall, these differences are small and we can feel confident about the numerical model.

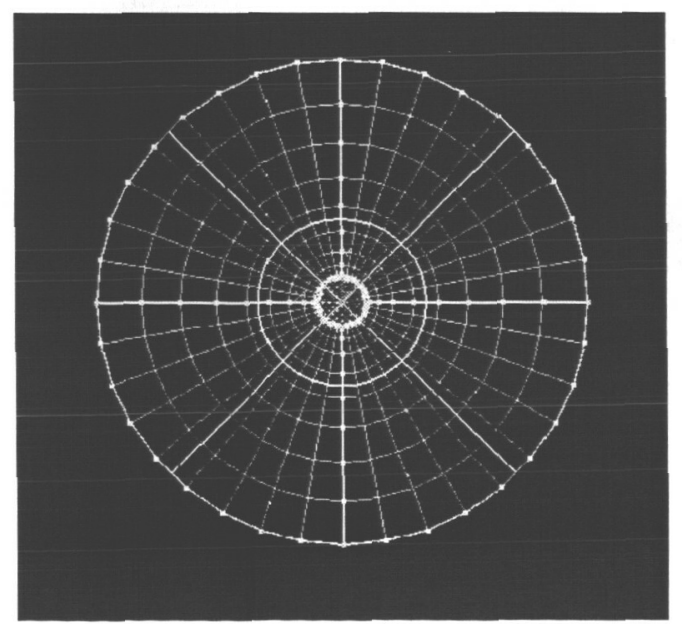

Figure 1: Computational grid in the cross plane for Reynolds number 10,000. 


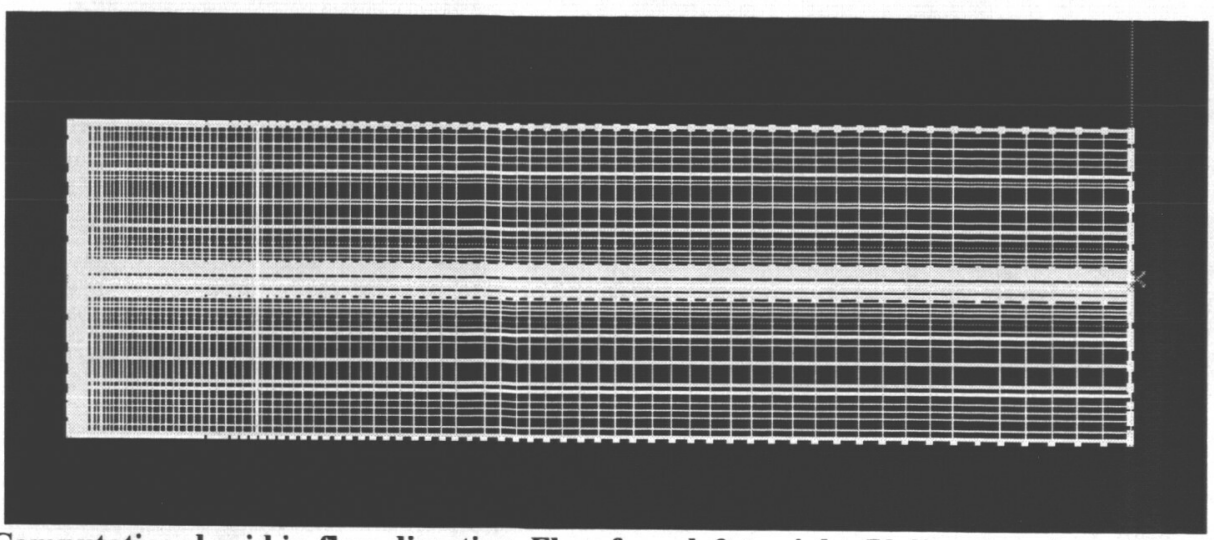

Figure 2: Computational grid in flow direction. Flow from left to right (Y direction skewed by factor of 5).

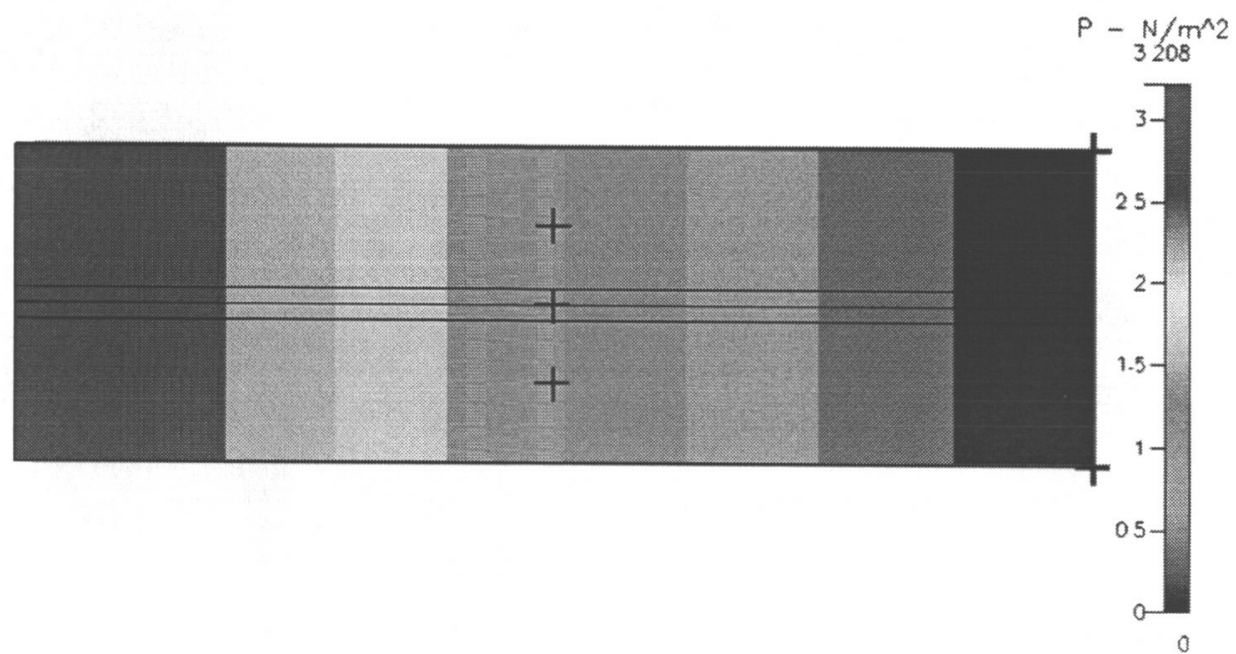

Figure 3a

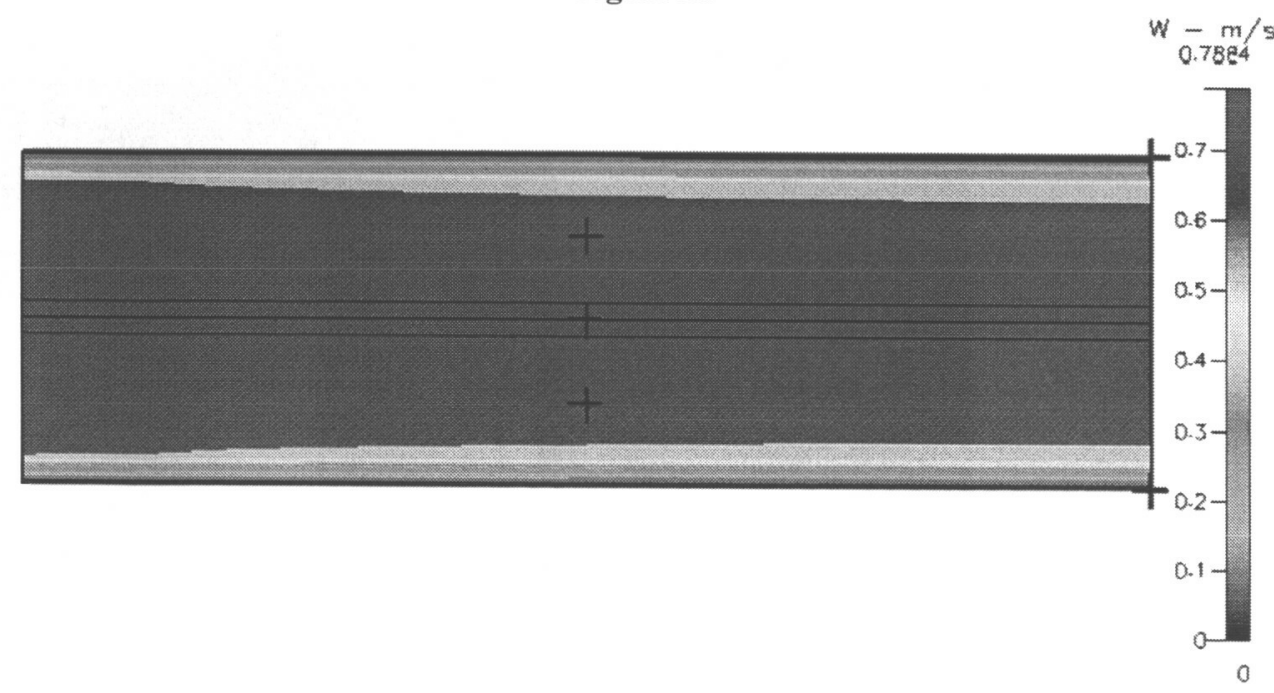

Figure 3b 


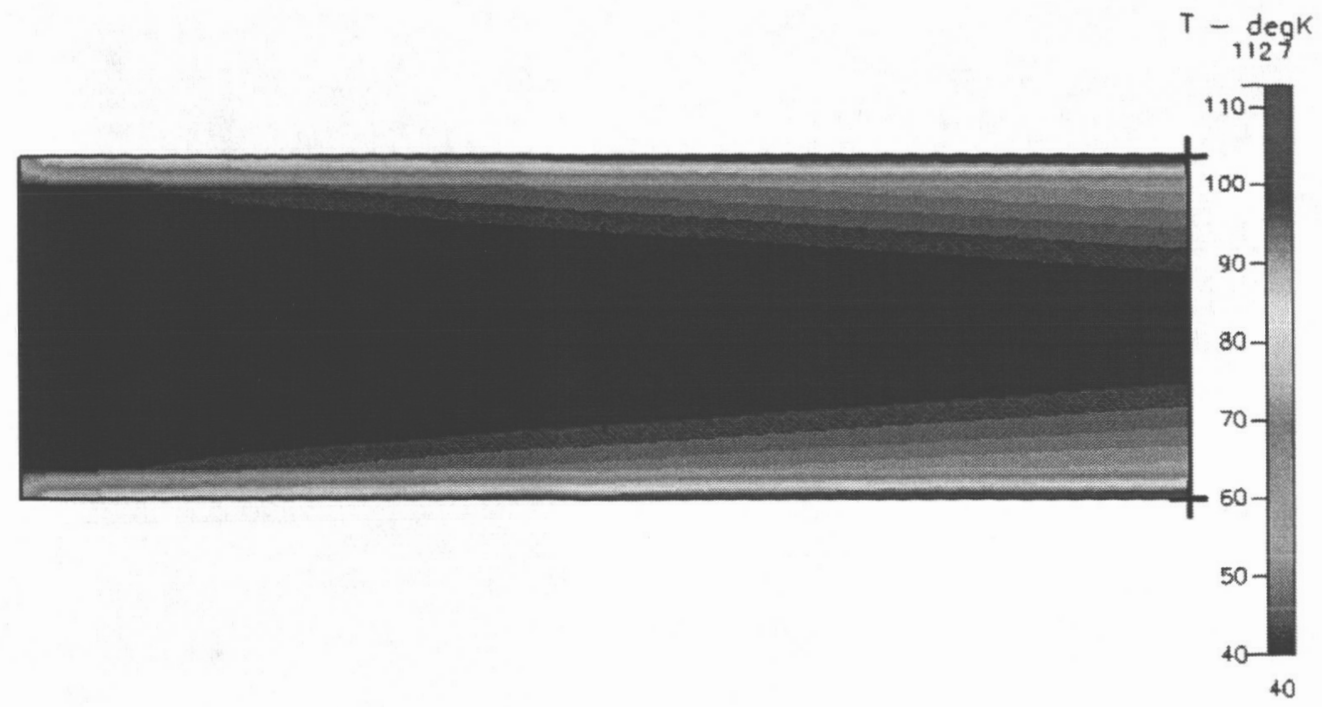

Figure 3c

Figure 3: Streamwise plots of the pressure, velocity, and temperature down the center plane.

\section{Results and Future Plans}

Now that the code has been show to be capable of predicting turbulent channel flow, we can now proceed to looking at several different cross-sectional shapes and channel curvature. This parametric study of aspect ratio holds the cross sectional area fixed. Also, the length of the tube considered will remain fixed. Table 2 shows a list of different aspect ratios and curvatures and the current status of each trial.

\begin{tabular}{|c|c|c|c|c|}
\hline & \multicolumn{4}{|c|}{ Reynolds number 10,000} \\
\hline Aspect Ratio & $\begin{array}{l}\text { Straight } \\
600 / 300\end{array}$ & $\begin{array}{c}90 \text { Deg bend } \\
600 / 300\end{array}$ & $\begin{array}{l}\text { Straight } \\
300 / 300\end{array}$ & $\begin{array}{c}90 \text { Deg bend } \\
300 / 300\end{array}$ \\
\hline 1.5 to 1 & Complete & Complete & Complete & Complete \\
\hline \multicolumn{5}{|l|}{5 to 1} \\
\hline \multicolumn{5}{|l|}{8 to 1} \\
\hline \multirow{2}{*}{\multicolumn{5}{|c|}{ Reynolds number 500,000}} \\
\hline & & & & \\
\hline Aspect Ratio & $\begin{array}{l}\text { Straight } \\
600 / 300\end{array}$ & $\begin{array}{c}90 \text { Deg bend } \\
600 / 300\end{array}$ & $\begin{array}{l}\text { Straight } \\
300 / 300\end{array}$ & $\begin{array}{c}90 \text { Deg bend } \\
300 / 300\end{array}$ \\
\hline \multicolumn{5}{|l|}{1.5 to 1} \\
\hline \multicolumn{5}{|l|}{5 to 1} \\
\hline \multicolumn{5}{|l|}{8 to 1} \\
\hline 10 to 1 & & & & \\
\hline
\end{tabular}

Table 2: Trial status table

Since the overall progress is somewhat in the beginning stages, not much can be said about how aspect ratio effects heat transfer and pressure drop. Figure 4 and Figure 5 are some temperature plots near the exit from the straight and 90 degree bend channels with wall temperature of $600 \mathrm{~K}$ and $300 \mathrm{~K}$. 


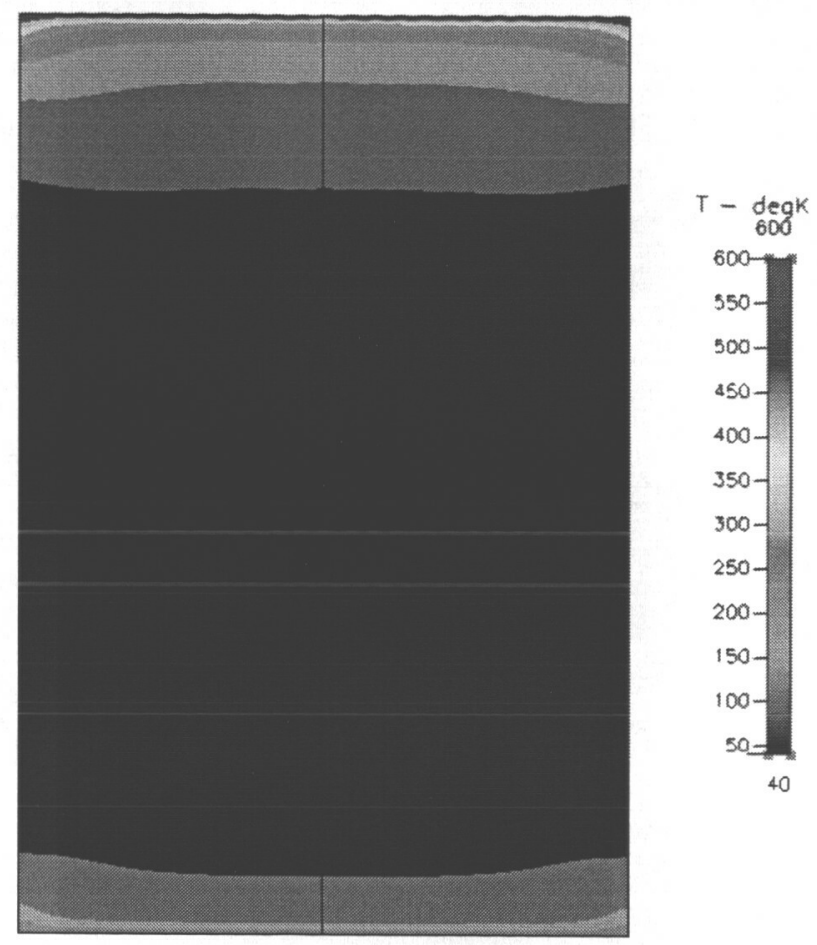

Figure 4: Straight Channel Near Exit Plane Temperature Contour

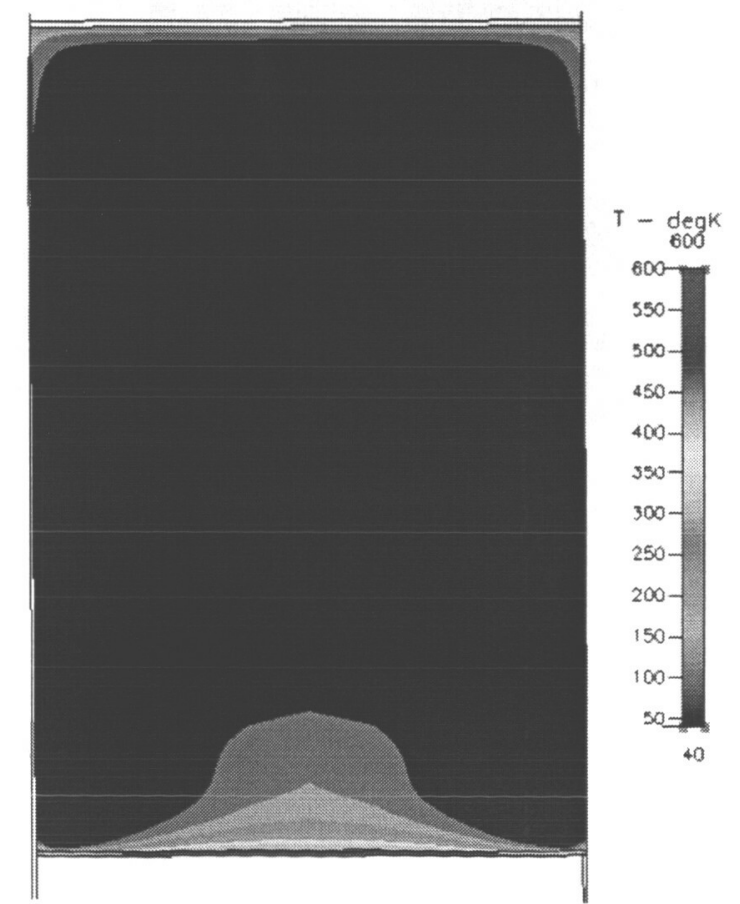

Figure 5: 90 Bend Channel Near Exit Plane Temperature Contour

6

American Institute of Aeronautics and Astronautics 


\section{Conclusion}

It is well known that there exists a secondary flow in high aspect ratio tubes with curvature ${ }^{6}$. With this secondary flow, more heat can be transferred from the hot combustor wall to the coolant channel. From Figure 4 and Figure 5 you can start to see some of the effects of this secondary flow. We have cooler liquid reaching the hot combustor wall and adding more heat into the centerplane shown in Figure 5. It is expected that as the aspect ratio increases, the more effective the cooling process will become. 


\section{Acknowledgments}

The work reported in this paper was supported by a contract from the National Aeronautics and Space Administration through the Constellation University Institutes Project (CUIP) and the Rocket Engine Advancement Program (REAP).

\section{References}

${ }^{1}$ Linstrom, P. J. and Mallard, W.G., Eds., NIST Chemistry WebBook, NIST Standard Reference Database Number 69,National Institute of Standards and Technology, Gaithersburg, MD, June 2005. (http://webbook.nist.gov).

${ }^{2}$ Incorpera, Frank P., and DeWitt, David P., Fundamentals of Heat and Mass Transfer, $5^{\text {th }}$ ed., John Wiley \&Sons, New York, 2002, Chap 8.

${ }^{3}$ White, Frank M., Fluid Mechanics, $4^{\text {th }}$ ed., McGraw-Hil, New York, 1999, Chap 6.

${ }^{4}$ Yagley, J., Feng, J., and Merkle, C. L., "The effect of Aspect Ratio on the Effectiveness of Combustor Coolant Passages," AIAA Paper 92-3153, AIAA/SAE/ASME/ASEE $28^{\text {th }}$ Joint Propulsion Conference and Exhibit, Nashville, TN .,July 6-8, 1992.

${ }^{5}$ Yagley, J., Feng, J., and Merkle, C. L., "CFD Analyses of Coolant Channel Flowfields," AIAA Paper 93-1830, AIAA/SAE/ASME/ASEE $29^{\text {th }}$ Joint Propulsion Conference and Exhibit, Monterey, CA., June 28-30, 1993.

${ }^{6}$ Meyer, Michael L., "Visualization of Secondary Flow Development in Huge Aspect Ratio Channels with Curvature," AIAA Paper 94-2979, AIAA/SAE/ASME/ASEE $30^{\text {th }}$ Joint Propulsion Conference, Indianapolis, IN., June 27-29, 1994.

${ }^{7}$ Meyer, Michael L., "Electrically Heated Tube Investigation of Cooling Channel Geometry Effects," AIAA Paper 95-2500, AIAA/SAE/ASME/ASEE $31^{\text {th }}$ Joint Propulsion Conference and Exhibit, San Diego, CA., July 10-12, 1995.

${ }^{8}$ Humphrey, J. A. C., Taylor, A. M. K., and Whitelaw, J. H., "Laminar Flow in a Square Duct of Strong Curvature," Journal of Fluid Mechanics, Vol. 83, Part 3, 1977, pp. 509-527. 